\title{
Siegfried Haddenbrock
}

Soziale oder forensische Schuldfähigkeit

(Zurechnungsfähigkeit) 



\section{Soziale oder forensische Schuldfähigkeit (Zurechnungsfähigkeit)}

Zwei kriminalanthropologische Grundstudien

über Determination und Freiheit im Raum humaner Zeitlichkeit und

zur Funktion der Schuldfähigkeitsbestimmungen im deutschen Strafrecht

von

Siegfried Haddenbrock

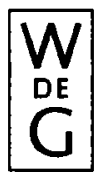

1992

Walter de Gruyter · Berlin · New York 
@ Gedruckt auf säurefreiem Papier, das die US-ANSI-Norm über Haltbarkeit erfültt.

Die Deutsche Bibliothek - CIP-Einheitsaufnabme

Haddenbrock, Siegfried:

Soziale oder forensische Schuldfähigkeit (Zurechnungsfähigkeit) : Zwei kriminalanthropologische Grundstudien über Determination und Freiheit im Raum humaner Zeitlichkeit und zur Funktion der Schuldfähigkeitsbestimmungen im deutschen Strafrecht / von Siegfried Haddenbrock. - Berlin ; New York : de Gruyter, 1992 ISBN 3-11-013611-2

(1) Copyright 1992 by Walter de Gruyter \& Co., D-1000 Berlin 30.

Dieses Werk einschließlich aller seiner Teile ist urheberrechtlich geschützt. Jede Verwertung außerhalb der engen Grenzen des Urheberrechtsgesetzes ist ohne Zustimmung des Verlages unzulässig und strafbar. Das gilt insbesondere für Vervielfältigungen, Übersetzungen, Mikroverfilmungen und die Einspeicherung und Verarbeitung in elektronischen Systemen.

\section{Printed in Germany}

Satz und Druck: Saladruck, 1000 Berlin 36

Bindearbeiten: Dieter Mikolai, 1000 Berlin 10

Umschlagentwurf: Thomas Beaufort, 2000 Hamburg 20 
Dem Andenken an

\section{Schwester Ellen}

Freiin von Freytag-Loringhoven

(1898-1941)

In schwerster Zeit bis zu ihrem Tod

I. Oberin

in der ehem. Heil- und Pflegeanstalt Göttingen 
